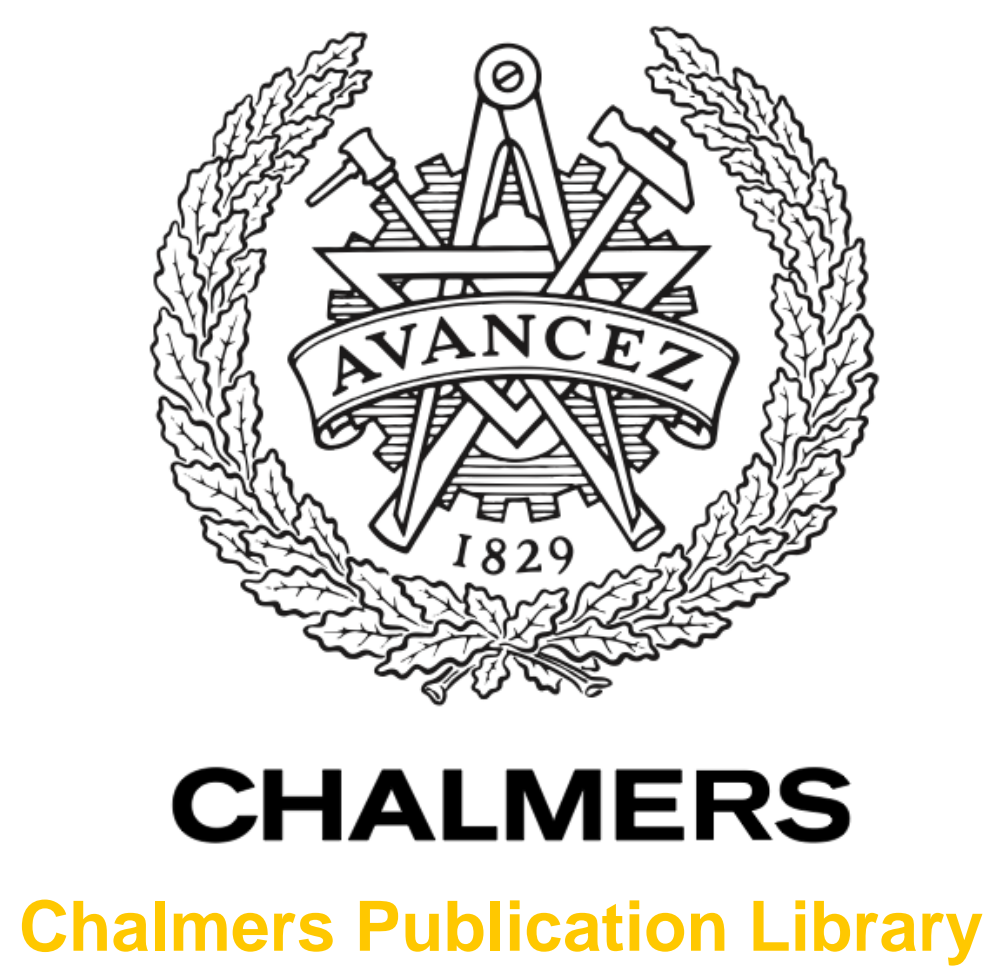

\title{
Novel nanostructured microfibrillated cellulose-hydroxypropyl methylcellulose films with large one-dimensional swelling and tunable permeability
}

This document has been downloaded from Chalmers Publication Library (CPL). It is the author's version of a work that was accepted for publication in:

\section{Carbohydrate Polymers (ISSN: 0144-8617)}

\section{Citation for the published paper:}

Larsson, M. ; Hjärtstam, J. ; Larsson, A. (2012) "Novel nanostructured microfibrillated cellulose-hydroxypropyl methylcellulose films with large one-dimensional swelling and tunable permeability". Carbohydrate Polymers

\section{http://dx.doi.org/10.1016/j.carbpol.2012.01.056}

Downloaded from: http://publications.lib.chalmers.se/publication/154774

Notice: Changes introduced as a result of publishing processes such as copy-editing and formatting may not be reflected in this document. For a definitive version of this work, please refer to the published source. Please note that access to the published version might require a subscription. 
Novel nanostructured microfibrillated cellulose - hydroxypropyl methylcellulose films

with large one-dimensional swelling and tunable permeability

Mikael Larsson ${ }^{\mathrm{a} *}$, Johan Hjärtstam ${ }^{\mathrm{b}}$, and Anette Larsson ${ }^{\mathrm{a}}$

${ }^{a}$ Department of Chemical and Biological Engineering, Chalmers University of Technology, 41296 Gothenburg, Sweden. E-mail: mikael.larsson@chalmers.se,

anette.larsson@chalmers.se

b AstraZeneca R\&D Mölndal, SE-43183 Mölndal, Sweden. E-mail:

Johan.Hjärtstam@astrazeneca.com

* Corresponding author. Department of Chemical and Biological Engineering, Chalmers

University of Technology, 41296 Gothenburg, Sweden. Fax: +46 31772 3418; Tel: +46

31772 1000; E-mail address: mikael.larsson@chalmers.se; larsson.mikael@ gmail.com 


\begin{abstract}
Microfibrillated cellulose (MFC) is a material that currently is subjected to extensive studies. This due to it being renewable, abundant and having interesting and useful properties derived from its nano to micro structure. However, to date few studies have investigated the potential and behavior of MFC in wet applications. Here we report that MFC films containing the water soluble and pharmaceutically approved polymer hydroxypropyl methylcellulose (HPMC) exhibited an unexpected decrease in permeability and excellent one-dimensional swelling properties above a threshold in HPMC content. The observed material characteristics are proposed to derive from that HPMC influences the aggregation behavior of MFC in such a way that above a critical HPMC content the films are created through self assembly into a layered structure, composed of low swelling layers with swellable inter layer regions. The suggested structures were supported by high resolution microscopy. The findings should hold potential for direct applications, but even more as a concept for future material design.
\end{abstract}

Keywords: Controlled release films, Diffusion, HPMC, MFC, Swelling, Permeability 


\section{Introduction}

Today there is a great interest in finding new renewable materials to be used in various applications. One renewable material of interest is microfibrillated cellulose (MFC), which is prepared by disintegration of native cellulose into smaller fibril aggregates or even individual fibrils (Abdul Khalil, Bhat \& Ireana Yusra. 2011; Herrick, Casebier, Hamilton \& Sandberg, 1983; Ikkala et al., 2009; Pääkkö et al., 2007; Siró \& Plackett, 2010; Turbak, Snyder \& Sandberg, 1983). The resulting product will differ greatly in dimensions depending on the origin of the native cellulose, history of the sample and the method used for microfibrillation (Abdul Khalil, Bhat \& Ireana Yusra, 2011; Brown, 2004; Henriksson, Henriksson, Berglund \& Lindström, 2007; Hult, Larsson \& Iversen, 2001; Siró \& Plackett, 2010; Syverud, ChingaCarrasco, Toledo \& Toledo, 2011). None the less, the huge aspect ratio, interesting mechanical and surface properties of MFC fibers, in combination with that cellulose is one of the most abundant biopolymers on earth (Siró \& Plackett, 2010), has lead to extensive research interest on MFC and it has been found to be a promising nano-scale reinforcement material for polymers (Siró \& Plackett, 2010). In the area of films and coatings it has been shown that MFC-films exhibits promising gas barrier properties (Aulin, Gällstedt \& Lindström, 2010; Belbekhouche et al., 2011; Fukuzumi, Saito, Iwata, Kumamoto \& Isogai, 2008; Siró, Plackett, Hedenqvist, Ankerfors \& Lindström, 2010), as well as oil barrier properties (Aulin, Gällstedt \& Lindström, 2010). Furthermore, water vapor diffusion in pure and composite MFC films has been shown to be low, as seen in the work by others (Belbekhouche et al., 2011; Bilbao-Sainz, Bras, Williams, Sénechal \& Orts, 2011; Minelli et al., 2010; Svagan, Hedenqvist \& Berglund, 2009).

Regarding the wet state, it is well known that MFC suspensions form strong hydrogels even at low concentrations (Agoda-Tandjawa et al., 2010; Ikkala et al., 2009; Ono, Shimaya, Sato \& Hongo, 2004) and it has been shown that MFC can strongly augment the properties of 
composite hydrogels (Harini \& Deshpande, 2009; Larsson, Stading \& Larsson, 2010). Despite this fact and the previously mentioned studies on mass transport in solid state films, there are to the authors' knowledge no studies on the permeability of, or diffusion in, MFC containing films in the wet state. This is surprising as beneficial results would open for applications in the field of controlled release. An example is the pharmaceutical industry where film coating formulations are commonly used to achieve desired release profiles of drugs (Felton, 2006; Hjärtstam \& Hjertberg, 1999; Larsson, Hjärtstam, Berndtsson, Stading \& Larsson, 2010; Sakellariou \& Rowe, 1995). The drug release from such formulations is controlled by the diffusion properties of the films, which in turn are determined by the porosity and structure of the films (Hjärtstam \& Hjertberg, 1999; Marucci, Hjärtstam, Ragnarsson, Iselau \& Axelsson, 2009; Shinji, Hiroyuki, Yoshiyuki \& Kazuo, 1994). For extended release it is common that the films are formed from a water insoluble film-forming polymer and a pore-forming agent, where the ratio between the two can be varied to change the release profile. One class of commonly used pore formers is water soluble cellulose derivatives, such as hydroxypropyl methylcellulose (HPMC) and hydroxypropyl cellulose (HPC) (Marucci, Hjärtstam, Ragnarsson, Iselau \& Axelsson, 2009; Sakellariou \& Rowe, 1995; Sakellariou, Rowe \& White, 1986).

In this study we set out to investigate if MFC have the potential to be used as the water insoluble component in controlled release films by determining the water permeability of MFC films. Furthermore, it was investigated how different amounts ( 0 - $80 \% \mathrm{w} / \mathrm{w})$ of HPMC could be used to tune the permeability of such films. From a conventional point of view, it would be expected that HPMC act as an ordinary pore former that is released from the films upon contact with the dissolution medium. This would leave pores in the film, with the associated increase in permeability. However, as HPMC is an associative polymer that forms complexes between and within polymer chains (Larsson, Viridén, Stading \& Larsson, 2010; 
Viridén, Wittgren, Andersson, Abrahmsen-Alami \& Larsson, 2009), it was reasoned that it could potentially also interact strongly to the MFC in the films. This especially given the similarity of the materials, un-substituted regions of the HPMC could form hydrogen bonds with the MFC surfaces, as have been suggested to occur between HPMC and cellulose whiskers (Bilbao-Sainz, Bras, Williams, Sénechal \& Orts, 2011). In addition, we have seen strong interactions of MFC with polymers in a previously studied MFC-polyacrylic acid hydrogel system (Larsson, Stading \& Larsson, 2010). If HPMC did bind strongly to the MFC, it would not leave the films, but would instead gel inside the films in a manner similar to previously described interfacial gelation of HPMC (Dow, 2002; Kato, Kozaki \& Takahashi, 1986). This would lead to gel blocking of the inherent pores of the MFC films. If this occurred the permeability of the films could actually decrease with added HPMC, a similar phenomenon was observed by us when controlled release films composed of ethyl cellulose and hydroxypropyl cellulose were exposed to ethanol, though in that study it was swelling of the water insoluble ethyl cellulose that caused the gel blocking (Larsson, Hjärtstam, Berndtsson, Stading \& Larsson, 2010).

The structure of the MFC-HPMC films was characterized after preparation by scanning electron microscopy (SEM) and atomic force microscopy (AFM). The water permeability of the films was determined using a modified Ussing chamber, utilizing tritiated water as the diffusing probe. Swelling of the films was analyzed using both gravimetrical analysis and microscopy observations. The release of HPMC from the films was analyzed using size exclusion chromatography, multiangle light scattering, coupled with refractive index detection (SEC-MALS-RI), as well as through gravimetric analysis. The structure of the films after submersion was analyzed using SEM on both dried and freeze dried samples. The analyses revealed that the permeability did decrease with increasing HPMC content, and that unexpected swelling and structural properties were the underlying reason. 


\section{Theory}

The permeability of a film is closely related to the diffusion of the solute. Fick's first law of diffusion for ideal solutions is:

$j=-D \frac{d c}{d z}$

where $j$ is the flux per unit area, $D$ is the diffusion coefficient $c$ is concentration of the diffusing specie and $z$ is the direction of diffusion. However, a film is rarely a homogeneous system with a constant diffusion coefficient within the film. Furthermore, the effective diffusion length through a film will depend on the pore structure within the film; longer effective diffusion length will cause an apparently lower diffusion coefficient through the film. Thus the diffusion across a film should be replaced with an effective diffusion coefficient $D_{e}$. The effective diffusion coefficient is, with some variations in notations, commonly expressed as:

$D_{e}=\frac{D_{p} \varepsilon F(\lambda)}{\tau^{2}}$

where $D_{p}$ is defined as the diffusion coefficient of the permeant in solution (Kushner, Blankschtein \& Langer, 2007; Saripalli, Serne, Meyer \& McGrail, 2002; Shen \& Chen, 2007) or in the membrane (Peck, Ghanem \& Higuchi, 1994), where the latter should be more suitable for pores filled with media significantly different from the surrounding solution, $\varepsilon$ is the porosity, $F(\lambda)$ is a hindrance factor, $\lambda$ is defined as the ratio of the hydrodynamic radius of the permeant and the effective pore radius of the film and $\tau$ is the tortousity defined as:

$$
\tau=\frac{L_{e}}{L_{0}}
$$

where $L_{e}$ is the effective diffusion path for the permeant upon crossing the film, and $L_{0}$ is the thickness over which diffusion occur, i.e. the film thickness in this work. In some literature $F(\lambda)$ is derived from hydrodynamic theories under the assumption that the solute is large as 
compared to the solvent, and that the solvent thus can be treated as a continuum (Dechadilok \& Deen, 2006). However, this is not always a fair assumption. In other literature the hindrance factor is more qualitatively described as being derived from pore volume through which diffusion does not readily occur (Saripalli, Serne, Meyer \& McGrail, 2002), leading to an effective porosity.

For the steady state diffusive flow across a film the following equation can be derived for ideal behavior:(Cussler, 2009)

$J=\frac{D_{e} A}{h}\left(c_{d}-c_{a}\right)$

where $A$ is the area across which diffusion occurs, $h$ is the film thickness, $c_{d}$ and $c_{a}$ are the concentrations of the diffusing specie in the donor and acceptor solution, respectively. The diffusive flow across a film is commonly written in terms of permeability, $P$ so that:

$J=P A\left(c_{d}-c_{a}\right)$

where the permeability coefficient by recognition with Eq. 4 is:

$P=\frac{D_{e}}{h}$

\section{Materials and methods}

\subsection{Materials}

Micro fibrillated cellulose (MFC) was bought from the Paper and Fibre Research Institute PFI, Trondheim, Norway. The MFC had been prepared from commercial bleached kraft pulp using a mechanical pre-treatment followed by homogenization according to Eriksson et al (Eriksen, 2008), and has previously been characterized as highly heterogeneous (Larsson, Stading \& Larsson, 2010). The used hydroxypropyl methylcellulose (HPMC) was of the grade 90 SH 100 SR, Shin-Etsu Chemical Co., Ltd., Tokyo, Japan. Water used in the permeability analyses was ultrapure deionized (Maxima USF, Elga, UK), in the swelling and 
release experiments deionized water was used. Phosphate buffer for SEC-RI analysis was prepared from analytical grade ingredients. Tritiated water (PerkinElmer, USA) was used as the diffusing specie in the water permeability measurements.

\subsection{Film preparation}

HPMC and MFC were prepared to stock solutions with $0.4 \%$ w/v. The stock solutions were mixed to achieve HPMC concentrations of $0,20,35,50,65$ and $80 \% \mathrm{w} / \mathrm{w}$ in the formed films. From the solutions $45 \mathrm{~g}$ were poured into $100 \mathrm{ml}$ weigh boats (VWR, Stockholm, Sweden). The films were acquired by keeping the solutions at $30{ }^{\circ} \mathrm{C}$ in a desiccator with freshly dried silica gel orange (Sigma-Aldrich, Steinheim, Germany) until dry (about 3 weeks), the silica gel was replenished every three days. To minimize errors from preparation all samples compared within one analysis run were always prepared simultaneously in the same desiccator. The films were stored in desiccators with Silica gel orange in between measurements.

\subsection{Atomic force microscopy (AFM)}

AFM analysis of the prepared films was performed using a Digital Instrument Nanoscope IIIa with a type G scanner (Digital Instrument Inc.). The cantilever used was a Mikro Masch silicon cantilever NSC 15. The AFM was operated at a resonance frequency of about $330 \mathrm{kHz}$ in tapping mode, the scan rate was $1 \mathrm{~Hz}$ and the measurements were performed in air.

\subsection{Water permeability analysis}

The water permeability of the films was analyzed using a modified Ussing chamber with the setup previously described (Hjärtstam \& Hjertberg, 1999). Briefly, a film sample was 
placed between a donor and acceptor compartment. The initial film thickness was determined as the average of five measurements using an IP 54 micrometer (Mitutoyo, Japan). Initially 15 $\mathrm{ml}$ of $\mathrm{H}_{2} \mathrm{O}$ was added simultaneously to both the donor and the acceptor compartments, two paddles were used to stir the contents of the two chambers at a speed of about $200 \mathrm{rpm}$. After 5 minutes a small amount of tritiated water $(10 \mu \mathrm{l}, 400 \mathrm{kBq})$ was added to the donor compartment. At specified times $500 \mu \mathrm{l}$ sample was taken from the acceptor compartment and was replaced by the same amount of water. The temperature was maintained at $37{ }^{\circ} \mathrm{C}$ through the analyses. The samples extracted at the different times were weighed and analyzed in a scintillator counter (1414 LSC, Win Spectral, Wallac). From the tritium activity registered in the acceptor compartment at the different times, the amount of water that had diffused through the film at each time could be determined. The permeability was subsequently calculated as the average of the permeability between each two measure points, using Eq. 5 .

\subsection{Swelling of films}

For determination of swelling and weight loss during swelling, rectangular film pieces were cut out and the dry weights ranging from 4-10 mg were recorded using a Shimadzu AUW220D (Shimadzu Philippines Manufacturing Inc., Philippines). The films were swollen in $5 \mathrm{ml}$ water in Non-Tissue Culture Treated Plates, 12 Well, Flat bottom with Low Evaporation Lid (Becton Dickinson and Company, Franklin Lakes, USA). The swelling was conducted at $37{ }^{\circ} \mathrm{C}$ and shaking at $300 \mathrm{rpm}$ using a Grant-bio PHMP-4 (Grant Instruments Ltd., Cambridge, UK). At specified times, in the range $10 \mathrm{~min}$ to $24 \mathrm{~h}$, the weights of the swollen samples were recorded and the swelling degree per initial weight was calculated as:

$Q_{i}=\frac{\left(m-m_{i}\right)}{m_{i}}$

where $m$ is the wet mass of the film and $m_{i}$ is the initial dry weight of the film. The samples were then dried and the swelling degree per actual dry weight was calculated as: 
$Q_{\text {real }}=\frac{\left(m-m_{d r y}\right)}{m_{d r y}}$

where $m_{\mathrm{dry}}$ is the weight of the dried film. Samples submerged for $24 \mathrm{~h}$, and subsequently dried, were also re-swollen and the degree of swelling was again calculated using Eq. 7 and 8.

To investigate dimensional changes upon swelling, small rectangular film pieces were cut out and the initial and swollen thickness was determined by observing the edge using a microscope. The initial film thicknesses were determined using an Olympus BH2 research microscope with a Microscope digital camera system DP12 (Olympus) in reflectance mode. The film thickness of samples submerged for $3 \mathrm{~h}$, as described for mass uptake determination, was determined using a USB-microscope (Digimicro, China), using an in-image reference of known dimension to determine sample dimensions. The one-dimensional swelling of the film, the change in film thickness, was then calculated as:

$Q_{h}=\frac{\left(h-h_{i}\right)}{h_{i}}$

where $h$ is the wet thickness of the film and $h_{i}$ is the initial thickness of the dry film.

3.6 Size exclusion chromatography, multiangle light scattering, refractive index detection $(S E C-M A L S-R I)$

The release of HPMC from the films was determined accordingly; film pieces were cut out and their dry weights recorded. The film pieces were then subjected to USP release studies; $500 \mathrm{ml}$ phosphate buffer, $\mathrm{pH} 6.8,75 \mathrm{rpm}, 37^{\circ} \mathrm{C}$. Samples were taken out at specified time points and were analyzed with regard to HPMC concentration using a SEC-MALS-RI system. The column used was a TSKgel GMPWxl 7.8mmx300mm 13um (TOSOHAAS, Germany). The MALS used was a DAWN EOS (Wyatt Technology, Santa Barbara, USA) and the RI detector was an OPTILAB rEX (Wyatt Technology, Santa Barbara, USA). 
SEM analysis of films after preparation and after submersion for $3 \mathrm{~h}$ in the Ussing chambers were conducted using a LEO Ultra 55 SEM equipped with a field emission gun (LEO Electron Microscopy Group, Germany) in secondary electron detection mode. The submerged films were prepared for analysis both by drying at $70{ }^{\circ} \mathrm{C}$ and by freezing at $-32{ }^{\circ} \mathrm{C}$ followed by freeze drying using a Jouan LP3 freeze dryer (Jouan, France). Prior to SEM analysis all samples were sputter coated with gold in Argon atmosphere for about 1 min using a S150B Sputter Coater (Edwards, England).

\section{Results and discussion}

\subsection{Water permeability analysis}

Films composed of MFC, with varying amount of the conventionally pore forming water soluble polymer $\operatorname{HPMC}(0,20,35,50,65$ and $80 \% \mathrm{w} / \mathrm{w})$ were subjected to water permeability analysis using a modified Ussing camber with tritiated water as the diffusing probe. Films with $\leq 50 \%$ HPMC were durable and kept their integrity throughout the $3 \mathrm{~h}$ analysis, showing no tendency to break. The diffusive flow through the films was close to constant as seen in the exemplifying Fig. 1. Films with > 50\% HPMC were increasingly fragile and could only be analyzed for about $1 \mathrm{~h}$ before breaking. However, those films did show a constant diffusive flow up to the point of rupture. It was found that the permeability normalized for initial film thickness $\left(P_{N}\right)$ was similar for 0 and $20 \%$ w/w HPMC. For higher HPMC contents $P_{N}$ in fact decreased more than twofold, in strong contradiction with what would normally be expected with increasing content of water soluble polymer (Parmar, Rane, Dias \& Rajabi-Siahboomi, 2010; Sakellariou \& Rowe, 1995). For HPMC contents of 35 - 80 $\% \mathrm{w} / \mathrm{w}$ the permeability was similarly reduced, but with a small minimum for $50 \% \mathrm{w} / \mathrm{w}$ HPMC (see Fig. 2). Of great interest is that the investigated films exhibited $P_{N}$ values in the range of those reported for currently used controlled release polymer film systems (Larsson, 
Hjärtstam, Berndtsson, Stading \& Larsson, 2010; Marucci, Hjärtstam, Ragnarsson, Iselau \& Axelsson, 2009).

It was observed, by visual inspection, that all the films had turned white during the analyses and that a considerable swelling had occurred in the z-direction of films containing $\geq$ $35 \%$ w/w HPMC. As seen from Eq. 6, an increased film thickness would lead to a decrease in the observed permeability if the other parameters were constant. However, it is well known that the diffusion coefficient $(D)$ in a swollen polymer matrix increases with decreasing polymer concentration (Masaro \& Zhu, 1999; Muhr \& Blanshard, 1982). Furthermore, the swelling of the films would also lead to increase of the porosity $(\varepsilon)$. An increase in either $D$ or $\varepsilon$ would lead to an increase in permeability. To separate the mechanisms behind the unconventional decrease in permeability with increasing HPMC content and to investigate if HPMC did in fact remain in the film pores, HPMC release studies and swelling analyses were conducted.

\subsection{HPMC release and swelling analyses}

SEC-MALS-RI analysis of HPMC release from films containing 20, 35 and $65 \% \mathrm{w} / \mathrm{w}$ HPMC revealed that some, but not all, of the HPMC was release from the films; see Fig. 3. The percentage of HPMC released was in good agreement with calculations based on weight loss after swelling for pure MFC films and films containing HPMC, assuming that the fraction of MFC lost was constant (supplementary data). A larger percentage of the HPMC was released from films with higher HPMC content. This indicates that interactions between MFC and HPMC are the cause for retention of some HPMC within the films. Given that the MFC exists as particles such interactions should occur at the surfaces of the MFC. Thus, it would be expected that samples with a higher surface area of the MFC content would release less HPMC per MFC. When calculating the mass HPMC retained within the films after $24 \mathrm{~h}$ 
per mass of initial MFC, the quotients $0.14,0.26$ and 0.41 were acquired for films with 20, 35 and $65 \% \mathrm{w} / \mathrm{w}$ HPMC, respectively. Indeed, it seems as if films with higher HPMC content had formed different structures during the film forming process and as if those structures had an increased MFC surface area with which HPMC could interact, possibly due to HPMC preventing the aggregation of MFC during film formation. This explanation is supported by other publications where the aggregation of cellulose microfibrils is described to be prevented by the presence of other polymers. Co-crystallization between bacterial cellulose fibers was reported to be inhibited in the presence of hydroxyethylcellulose (Zhou et al., 2009) and hemicelluloses were reported to prevent the coalescence of cellulose microfibrills during drying (Iwamoto, Abe \& Yano, 2008).

Swelling analyses were conducted on films containing $0-65 \%$ w/w HPMC, the film with $80 \%$ w/w HPMC was excluded due to its very fragile nature. The swelling analyses were based on mass uptake/loss and dimensional changes as observed by optical microscopy. It was found that all samples displayed very quick initial swelling and that the swelling per initial dry weight $\left(Q_{i}\right)$ increased dramatically for HPMC contents $\geq 35 \% \mathrm{w} / \mathrm{w}$ (Fig. 4a). The dimensional changes of films swollen for $3 \mathrm{~h}$ revealed that most of the swelling took place by increasing the thickness $(h)$ of the films; see Fig. 4b. The films were re-dried and the swelling per actual material present within the wet films was calculated $\left(Q_{\text {real }}\right)$. The acquired $Q_{\text {real }}$ values were surprisingly large for films with HPMC contents $\geq 35 \% \mathrm{w} / \mathrm{w}$, and were in fact as high as $52 \mathrm{~g} / \mathrm{g}$ for the film with $65 \% \mathrm{w} / \mathrm{w}$ HPMC (see Fig. 4c).

In order to evaluate if the huge swelling was an effect arising from the structure of the films and if this structure was retained upon swelling and subsequent drying, films swollen for $24 \mathrm{~h}$ were dried and re-swollen. As seen in Fig. $4 \mathrm{~d}$ the swelling $\left(Q_{\text {real }}\right)$ was not retained for reswollen samples, but some small increase of the swelling was still present with increasing initial HPMC content. As such, it can be concluded that the extremely large swelling for films 
with $\geq 35 \% \mathrm{w} / \mathrm{w}$ HPMC was derived from the structure present in the films after preparation, and that this structure was altered upon swelling and subsequent drying. A probable cause for this loss of structure is that fine structures aggregated as contacts formed during drying. This seems likely as MFC is known to form aggregates upon drying (Hult, Larsson \& Iversen, 2001; Larsson, Stading \& Larsson, 2010; Minelli et al., 2010).

\subsection{Characterization of film structure after preparation}

To draw conclusions on how the structure of the prepared films varied with different HPMC contents films with 0, 20, and $50 \% \mathrm{w} / \mathrm{w}$ HPMC were analyzed after preparation using AFM and SEM. Both analyses, applied at different length scales, revealed that the films were dense and non-porous on the investigated length scales (Supplementary material). Interestingly, the AFM micrographs revealed that samples with higher MFC content displayed more individual fibers in the structure. The AFM results support what was indicated by the swelling and HPMC release results, that the presence of high HPMC concentrations prevented aggregation of the MFC during film formation.

\subsection{Characterization of film structure after swelling}

To get further information on the structure of films in the swollen state, the structure that in fact causes the observed permeability and swelling, film samples with 0,20 , and $50 \%$ w/w HPMC were studied using SEM after submersion for $3 \mathrm{~h}$ in the Ussing chambers. The time was chosen as it was the upper limit for the permeability experiments, and because close to all of the swelling and HPMC release had already occurred within $3 \mathrm{~h}$ (see Fig. 3 and 4). In an attempt to preserve the structures of the swollen films they were freeze-dried prior to the SEM analysis. Since it is common that the structure of porous controlled release films in the wet state is simply analyzed by conventional drying, this method was investigated as well. It 
was found that conventional drying did change the structure of the films (supplementary material). This change in structure upon drying is in agreement with the swelling results that dried and re-swollen films exhibited a much lower swelling than films swollen after preparation.

The SEM analysis of the swollen and subsequently freeze-dried films revealed a highly porous structure for the pure MFC film, the pores having typical sizes of 100s of nanometers. The HPMC containing films displayed a more dense structure with increasing MFC content (Fig. 5). At first glance this may seem strange as the pore size generally should increase with decreasing volume fraction of network. However, there are several logical explanations in coherence with previously discussed results. First, if the presence of HPMC as suggested prevented the aggregation of MFC into larger structures, the resulting smaller fiber radii should have promoted a decreased pore size as discussed in works on pore sizes in fibrous matrixes (Chatterjee, 2010; Lazzara, Blankschtein \& Deen, 2000; Ogston, 1958). Second, not all the HPMC was released from the films. The remaining HPMC should have lead to a decrease in the observed pore size as it would also form a dry network structure upon drying. Finally, and maybe most importantly, SEM analysis of the cross-section of a swollen and freeze-dried film revealed a structure with stacked layers in the z-direction (see Fig. 6). One should be careful to interpret freeze-dried structures as describing the true structure of a wet sample. However, the swelling results showed that almost all of the film swelling occurred in the z-direction. This would be the case for a layered structure where the individual layers exhibited low swelling and deformability, but where the interlayer regions were readily swellable. Such behavior has been reported for a novel anisotropic hydrogel by Haque et al. (Haque, Kamita, Kurokawa, Tsujii \& Gong, 2010). For such a system swelling would mainly occur through water occupying the inter-layer spaces, pushing the layers apart (see schematic drawing in Fig. 7). Taken together the swelling results and the layered structure observed in 
SEM, strongly suggests that the network structure of the wet samples was of the layered form. This is further supported by the fact that a layered structure has been previously observed for dry MFC films and MFC-hydroxyethylcellulose composite films (Minelli et al., 2010; Sehaqui, Zhou \& Berglund, 2011), and that a layered nanofibril structure has been suggested as an explanation for decreased water vapor diffusion in nanofibril cellulose starch composites (Svagan, Hedenqvist \& Berglund, 2009). A layered structure would lead to locally higher MFC concentrations in the layers than suggested by the swelling $\left(Q_{\text {real }}\right)$. Since the SEM analyses would have been performed on the surface of a layer, this would further explain the observed decrease in pore size.

\subsection{Discussion on the mass transport through the films}

Taken together, the permeability results and the swelling results can through Eq. 6 be combined to calculate the effective diffusion coefficient $\left(D_{e}\right)$ as:

$D_{e}=P h$

where $h$ is the thickness of the swollen film, acquired by multiplying the initial thickness by $\left(Q_{h}+1\right)$. Given the small size of the penetrant, tritiated water, the hindrance factor $f(\lambda)$ is assumed to be 1 . The porosity is approximated as the weight fraction of water in the films, calculated as:

$\varepsilon=\frac{Q_{\text {real }}}{Q_{\text {real }}+1}$

The ratio of the diffusion coefficient and the second power of the tortousity is then acquired from Eq. 2 as:

$\frac{D_{p}}{\tau^{2}}=\frac{D_{e}}{\varepsilon}$

The calculated values of $D_{p} / \tau^{2}$ are shown in Fig. 8a. Compared with pure MFC films, the value of $D_{p} / \tau^{2}$ first increases for $20 \%$ w/w HPMC content. The value of $D_{p} / \tau^{2}$ then decreases for HPMC contents of 35 and $50 \%$ w/w. Finally, $D_{p} / \tau^{2}$ again increases for $65 \%$ 
w/w HPMC content.

Now it is assumed that $D_{p}$ is the self diffusion coefficient of water at $37{ }^{\circ} \mathrm{C}$, taken to be $\approx 3 \cdot 10^{-9} \mathrm{~m}^{2} \mathrm{~s}^{-1}$ by interpolation of the data by Simpson and Carr to $37{ }^{\circ} \mathrm{C}$ (Simpson \& Carr, 1958). It could be argued that the assumption is wrong, given that some HPMC remained in the films, likely in the gelled state, and that the diffusion therefore in fact occurred in gel filled pores. However, the volume fraction of polymer in such a gel would have been very low as known from the swelling studies. Based on theories on diffusion of small diffusants in dilute polymer gels, as summarized in reviews on the matter (Masaro \& Zhu, 1999; Muhr \& Blanshard, 1982), it can be concluded that the diffusion coefficient should have been very close to that of the pure solvent at the gel concentrations relevant for the swollen films. Thus, the assumption is justified.

From Eq. 12 the values of $\tau^{2}$ can now be calculated (see Fig. 8b). From theory and most experimental data it is expected that the tortousity generally decreases with increasing porosity (Boudreau \& Meysman, 2006; Saripalli, Serne, Meyer \& McGrail, 2002; Shen \& Chen, 2007). The calculated values in Fig. 8b reveal that for the sample with $20 \% \mathrm{w} / \mathrm{w}$ HPMC the expected trend is followed. However, for higher HPMC concentrations the $\tau^{2}$ values are rather constant despite dramatically increased porosity. In fact, the $\tau^{2}$ increases somewhat for samples with 35 and $50 \%$ w/w HPMC. This clearly indicates that there was a change in how the addition HPMC affected the film structure. It seems as if low concentrations of HPMC induced a less tortuous structure, with minor increase of swelling. Higher HPMC content on the other hand had little further effect on the tortousity, but mayor impact on the swelling.

The observed $\tau^{2}$ values are in good agreement with previously discussed results. Both since a structural transition is indicated for HPMC contents $\geq 35 \% \mathrm{w} / \mathrm{w}$, but also as the relatively high $\tau^{2}$ values, given the low network concentrations, indicates a longer effective 
diffusion length. One plausible explanation for the longer diffusive length is the layered structure indicated both by swelling and SEM analyses. A layered structure would increase the diffusive path of the permeant due to inter-layer diffusion in the xy-plane during crossing of the film; see the schematic drawing in Fig 8.

From the permeability results, the swelling results and the calculated tortousity taken together, it can be concluded that the highly surprising permeability effects observed were mainly derived from the high one-dimensional swelling of the films, increasing the film thickness $h$ in Eq. 6. However, if the highly swollen films did not have a relatively high tortousity, compared to what would be expected at the very low network concentrations in question, the same strong effects would not have been observed.

\section{Conclusions}

In this study it was shown that for of MFC-HPMC composite films the permeability normalized for initial film thickness surprisingly decreased with increasing HPMC content. Interestingly, the observed permeability values were in the same range as for film systems currently used in controlled drug delivery. The films with high HPMC contents were also shown to have great swelling capacity per weight network in the films, in fact being in the superabsorbent range. The observed permeability and swelling was explained in terms of HPMC affecting the nano- micro structure of the formed films by influencing the aggregation of MFC, probably with the MFC self assembling into fine layer-like structures.

The investigated system, MFC-HPMC, may be directly applicable to controlled release applications. In addition, the results of this study should be of great relevance for other material design applications, not least to fibrous superabsorbents. Possible future works are plentiful. Some examples would be to study the MFC-HPMC film system utilized in real controlled delivery applications, to investigate if similar behavior could be achieved for other 
material systems and to investigate mechanical properties of such systems for solid state applications. Finally, it would be interesting to see if similar properties could be achieved for fibrous superabsorbents, preferably by adding a non leachable polymer that in itself is superabsorbent. This being of importance as the leachable weight fraction would otherwise contribute to the initial weight but not to the actual swellable material.

\section{Acknowledgements}

This project is part of the VINN Excellence Centre SuMo Biomaterials (Supermolecular Biomaterials - Structure dynamics and properties). The financial support from the Centre is gratefully acknowledged. Further financial support was acquired from the Swedish Research Council and from Chalmers Bioscience Program, Chalmers University of Technology. We want to thank Dr. Per Jacobsson and Dr. Alexandar Matic at Applied Physics, Chalmers University of Technology for valuable discussions, Anette Welinder at AstraZeneca for her help with the SEC-MALS-RI analyses and Anders Mårtensson at Polymer Technology, Chalmers University of Technology for his assistance in the AFM and SEM analyses. 


\section{References}

Abdul Khalil, H. P. S., Bhat, A. H., \& Ireana Yusra, A. F. (2011). Green composites from sustainable cellulose nanofibrils: A review. Carbohydr. Polym. doi:10.1016/j.carbpol.2011.08.078 .

Agoda-Tandjawa, G., Durand, S., Berot, S., Blassel, C., Gaillard, C., Garnier, C., \& Doublier, J. L. (2010). Rheological characterization of microfibrillated cellulose suspensions after freezing. Carbohydr. Polym., 80(3), 677-686.

Aulin, C., Gällstedt, M., \& Lindström, T. (2010). Oxygen and oil barrier properties of microfibrillated cellulose films and coatings. Cellulose, 17(3), 559-574.

Belbekhouche, S., Bras, J., Siqueira, G., Chappey, C., Lebrun, L., Khelifi, B., Marais, S., \& Dufresne, A. (2011). Water sorption behavior and gas barrier properties of cellulose whiskers and microfibrils films. Carbohydr. Polym., 83(4), 1740-1748.

Bilbao-Sainz, C., Bras, J., Williams, T., Sénechal, T., \& Orts, W. (2011). HPMC reinforced with different cellulose nano-particles. Carbohydr. Polym., 86(4), 1549-1557.

Brown, R. M., Jr. (2004). Cellulose structure and biosynthesis: what is in store for the 21 st century? J. Polym. Sci., A, 42(3), 487-495.

Chatterjee, A. P. (2010). Nonuniform fiber networks and fiber-based composites: Pore size distributions and elastic moduli. J. Appl. Phys., 108(6), 063513.

Cussler, E. L. (2009). Diffusion: Mass Transfer in Fluid Systems. (3rd ed.) Cambridge: Cambridge University Press.

Dechadilok, P., \& Deen, W. M. (2006). Hindrance Factors for Diffusion and Convection in Pores. Ind. Eng. Chem. Res., 45(21), 6953-6959.

Dow Chemical Company (2002). METHOCEL Cellulose Ethers - Technical Handbook. The Dow Chemical Company, http://www.dow.com/dowwolff/en/pdfs/192-01062.pdf <accessed: 2012-01-10>. 
Eriksen, Ø., Syverud, K. and Gregersen, Ø (2008). The use of microfibrillated cellulose produced from kraft pulp as a strength enhancer in TMP paper. Nord. Pulp Paper Res. J., 23(3), 299-304

Felton, L. A. (2006). Film Coating of Oral Solid Dosage Forms. In J. Swarbrick (Ed.), Encyclopedia of Pharmaceutical Technology (pp. 1729-1747). New York and London: Informa Healthcare.

Fukuzumi, H., Saito, T., Iwata, T., Kumamoto, Y., \& Isogai, A. (2008). Transparent and High Gas Barrier Films of Cellulose Nanofibers Prepared by TEMPO-Mediated Oxidation. Biomacromolecules, 10(1), 162-165.

Haque, M. A., Kamita, G., Kurokawa, T., Tsujii, K., \& Gong, J. P. (2010). Unidirectional Alignment of Lamellar Bilayer in Hydrogel: One-Dimensional Swelling, Anisotropic Modulus, and Stress/Strain Tunable Structural Color. Adv. Mater., 22(45), 5110-5114.

Harini, M., \& Deshpande, A. P. (2009). Rheology of poly(sodium acrylate) hydrogels during cross-linking with and without cellulose microfibrils. J. Rheol., 53(1), 31-47.

Henriksson, M., Henriksson, G., Berglund, L. A., \& Lindström, T. (2007). An environmentally friendly method for enzyme-assisted preparation of microfibrillated cellulose (MFC) nanofibers. Eur. Polym. J., 43(8), 3434-3441.

Herrick, F. W., Casebier, R. L., Hamilton, J. K., \& Sandberg, K. R. (1983). Microfibrillated cellulose: morphology and accessibility. J. Appl. Polym. Sci. Appl. Polym. Symp., 37 (Proc. Cellul. Conf., 9th, 1982, Part 2), 797-813.

Hjärtstam, J., \& Hjertberg, T. (1999). Studies of the water permeability and mechanical properties of a film made of an ethyl cellulose-ethanol-water ternary mixture. J. Appl. Polym. Sci., 74(8), 2056-2062.

Hult, E. L., Larsson, P. T., \& Iversen, T. (2001). Cellulose fibril aggregation -- an inherent property of kraft pulps. Polymer, 42(8), 3309-3314. 
Ikkala, O., Ras, R. H. A., Houbenov, N., Ruokolainen, J., Pääkkö, M., Laine, J., Leskelä, M., Berglund, L. A., Lindström, T., ten Brinke, G., Iatrou, H., Hadjichristidis, N., \& Faul, C. F. J. (2009). Solid state nanofibers based on self-assemblies: From cleaving from selfassemblies to multilevel hierarchical constructs. Faraday Discuss., 143(Soft Nanotechnology), 95-107.

Iwamoto, S., Abe, K., \& Yano, H. (2008). The Effect of Hemicelluloses on Wood Pulp Nanofibrillation and Nanofiber Network Characteristics. Biomacromolecules, 9(3), 10221026.

Kato, T., Kozaki, N., \& Takahashi, A. (1986). Lubrication Enhancement by Surface Gelation of Thin Liquid Films of Methylcellulose and Hydroxypropyl Methylcellulose Solutions. Polymer Journal, 18(2), 189-191.

Kushner, J., Blankschtein, D., \& Langer, R. (2007). Evaluation of the porosity, the tortuosity, and the hindrance factor for the transdermal delivery of hydrophilic permeants in the context of the aqueous pore pathway hypothesis using dual-radiolabeled permeability experiments. J. Pharm. Sci., 96(12), 3263-3282.

Larsson, M., Hjärtstam, J., Berndtsson, J., Stading, M., \& Larsson, A. (2010). Effect of ethanol on the water permeability of controlled release films composed of ethyl cellulose and hydroxypropyl cellulose. Eur. J. Pharm. Biopharm., 76, 428-432.

Larsson, M., Stading, M., \& Larsson, A. (2010). High Performance Polysodium Acrylate Superabsorbents Utilizing Microfibrillated Cellulose to Augment Gel Properties. Soft Mater., 8(3), 207-225.

Larsson, M., Viridén, A., Stading, M., \& Larsson, A. (2010). The influence of HPMC substitution pattern on solid-state properties. Carbohydr. Polym., 82(4), 1074-1081.

Lazzara, M. J., Blankschtein, D., \& Deen, W. M. (2000). Effects of Multisolute Steric Interactions on Membrane Partition Coefficients. J. Colloid Interface Sci., 226(1), 112- 
122.

Marucci, M., Hjärtstam, J., Ragnarsson, G., Iselau, F., \& Axelsson, A. (2009). Coated formulations: New insights into the release mechanism and changes in the film properties with a novel release cell. J. Controlled Release, 136(3), 206-212.

Masaro, L., \& Zhu, X. X. (1999). Physical models of diffusion for polymer solutions, gels and solids. Prog Polym. Sci., 24(5), 731-775.

Minelli, M., Baschetti, M. G., Doghieri, F., Ankerfors, M., Lindström, T., Siró, I., \& Plackett, D. (2010). Investigation of mass transport properties of microfibrillated cellulose (MFC) films. J. Membr. Sci., 358(1-2), 67-75.

Muhr, A. H., \& Blanshard, J. M. V. (1982). Diffusion in gels. Polymer, 23(7), 1012-1026.

Ogston, A. G. (1958). The spaces in a uniform random suspension of fibres. Trans. Faraday Soc., 54, 1754-1757.

Ono, H., Shimaya, Y., Sato, K., \& Hongo, T. (2004). H spin-spin relaxation time of water and rheological properties of cellulose nanofiber dispersion, transparent cellulose hydrogel (TCG). Polym. J., 36(9), 684-694.

Pääkkö, M., Ankerfors, M., Kosonen, H., Nykänen, A., Ahola, S., Österberg, M., Ruokolainen, J., Laine, J., Larsson, P. T., Ikkala, O., \& Lindström, T. (2007). Enzymatic hydrolysis combined with mechanical shearing and high-pressure homogenization for nanoscale cellulose fibrils and strong gels. Biomacromolecules, 8(6), 1934-1941.

Parmar, J., Rane, M., Dias, V., \& Rajabi-Siahboomi, A. (2010). Formulation of Extended Release Multiparticulate Systems using Ethylcellulose. Pharma Times, 42(4), 34-39.

Peck, K. D., Ghanem, A.-H., \& Higuchi, W. I. (1994). Hindered Diffusion of Polar Molecules Through and Effective Pore Radii Estimates of Intact and Ethanol Treated Human Epidermal Membrane. Pharm. Res., 11(9), 1306-1314-1314.

Sakellariou, P., \& Rowe, R. C. (1995). Interactions in cellulose derivative films for oral drug 
delivery. Prog. Polym. Sci., 20(5), 889-942.

Sakellariou, P., Rowe, R. C., \& White, E. F. T. (1986). Polymer/polymer interaction in blends of ethyl cellulose with both cellulose derivatives and polyethylene glycol 6000. Int. J. Pharm., 34(1-2), 93-103.

Saripalli, K. P., Serne, R. J., Meyer, P. D., \& McGrail, B. P. (2002). Prediction of Diffusion Coefficients in Porous Media Using Tortuosity Factors Based on Interfacial Areas. Ground Water, 40(4), 346-352.

Sehaqui, H., Zhou, Q., \& Berglund, L. A. (2011). Nanostructured biocomposites of high toughness-a wood cellulose nanofiber network in ductile hydroxyethylcellulose matrix. Soft Matter, 7(16), 7342-7350.

Shen, L., \& Chen, Z. (2007). Critical review of the impact of tortuosity on diffusion. Chem. Eng. Sci., 62(14), 3748-3755.

Shinji, N., Hiroyuki, Y., Yoshiyuki, H., \& Kazuo, N. (1994). Porosity-controlled ethylcellulose film coating. II. Spontaneous porous film formation in the spraying process and its solute permeability. Int. J. Pharm., 104(2), 95-106.

Simpson, J. H., \& Carr, H. Y. (1958). Diffusion and Nuclear Spin Relaxation in Water. Phys.Rev., 111(5), 1201.

Siró, I., \& Plackett, D. (2010). Microfibrillated cellulose and new nanocomposite materials: a review. Cellulose, 17(3), 459-494.

Siró, I., Plackett, D., Hedenqvist, M., Ankerfors, M., \& Lindström, T. (2011). Highly transparent films from carboxymethylated microfibrillated cellulose: The effect of multiple homogenization steps on key properties. J. Appl. Polym. Sci., 119(5), 2652-2660.

Svagan, A. J., Hedenqvist, M. S., \& Berglund, L. (2009). Reduced water vapour sorption in cellulose nanocomposites with starch matrix. Compos. Sci. Technol., 69(3-4), 500-506.

Syverud, K., Chinga-Carrasco, G., Toledo, J., \& Toledo, P. G. (2011). A comparative study of 
Eucalyptus and Pinus radiata pulp fibres as raw materials for production of cellulose nanofibrils. Carbohydr. Polym., 84(3), 1033-1038.

Turbak, A. F., Snyder, F. W., \& Sandberg, K. R. (1983). Microfibrillated cellulose, a new cellulose product: properties, uses, and commercial potential. J. Appl. Polym. Sci. Appl. Polym. Symp., 37(Proc. Cellul. Conf., 9th, 1982, Part 2), 815-827.

Viridén, A., Wittgren, B., Andersson, T., Abrahmsen-Alami, S., \& Larsson, A. (2009). Influence of Substitution Pattern on Solution Behavior of Hydroxypropyl Methylcellulose. Biomacromolecules, 10(3), 522-529.

Zhou, Q., Malm, E., Nilsson, H., Larsson, P. T., Iversen, T., Berglund, L. A., \& Bulone, V. (2009). Nanostructured biocomposites based on bacterial cellulosic nanofibers compartmentalized by a soft hydroxyethylcellulose matrix coating. Soft Matter, 5(21), 4124-4130. 


\section{Figure legends}

Fig.1 Exemplifying plot of the volume of water having diffused across the film, here for a sample with $50 \%$ w/w HPMC and a thickness of $38 \mu \mathrm{m}$.

Fig. 2 Plot of the water permeability, normalized versus film thickness, for MFC-HPMC films with varying HPMC content. Error bars indicate one standard deviation $(\mathrm{n}=2-3)$.

Fig. 3 Percentage of HPMC released at different times for MFC-HPMC films with $20 \%(\circ)$, $35 \%(\Delta)$ and $65 \%(\times)$ w/w HPMC.

Fig. 4 Swelling behavior for MFC-HPMC films, depending on HPMC content. a) Water uptake per initial dry weight for films containing $0 \%(\bullet), 20 \%(\circ), 35 \%(\Delta), 50 \%(\bullet)$, and $65 \%(\times)$ w/w HPMC. b) Changes in film thickness upon swelling $(\bullet)$ and swelling per initial dry weight ( $($ ) for samples with different HPMC content after submersion for 3 h. c) Swelling per real dry weight for the samples in (a). d) Water uptake after $24 \mathrm{~h}$ for initially swollen films (white) and the same films re-swollen after drying (grey). Error bars indicate Min/Max (n=2).

Fig. 5 SEM images of swollen and subsequently freeze dried MFC HPMC films. Top row is acquired at a magnification of 10000X for samples with initial HPMC contents of (a) $0 \%$, (b) $20 \%$ and (c) $50 \% \mathrm{w} / \mathrm{w}$. Bottom row is acquired at a magnification of $100000 \mathrm{X}$ for samples with initial HPMC contents of (d) $0 \%$, (e) $20 \%$ and (f) $50 \%$ w/w.

Fig. 6 SEM image of the cross-section of a swollen and subsequently freeze dried MFC HPMC film with initial HPMC content of $50 \% \mathrm{w} / \mathrm{w}$. 
Fig. 7 Schematic drawing of the close to one-dimensional swelling of a film with layered structures composed of non-swelling lamellas and swelling inter layer regions. For the swollen state an example of the tortuous path experienced by a penetrant (illustrated as a sphere) crossing the film is shown.

Fig. 8 Plots of values calculated from experimental data for (a) $D_{p} / \tau^{2}$ and (b) $\tau^{2}$ 
Figure 1

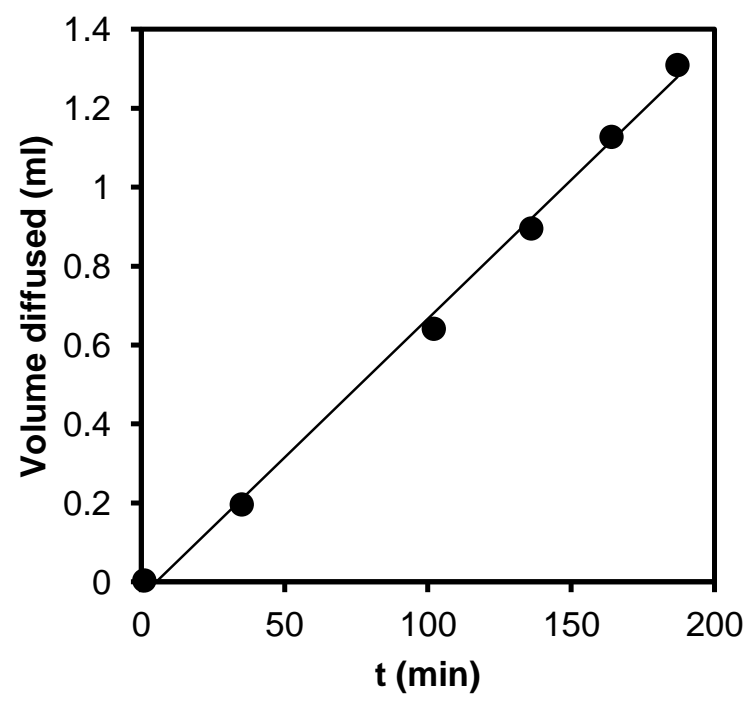


Figure 4
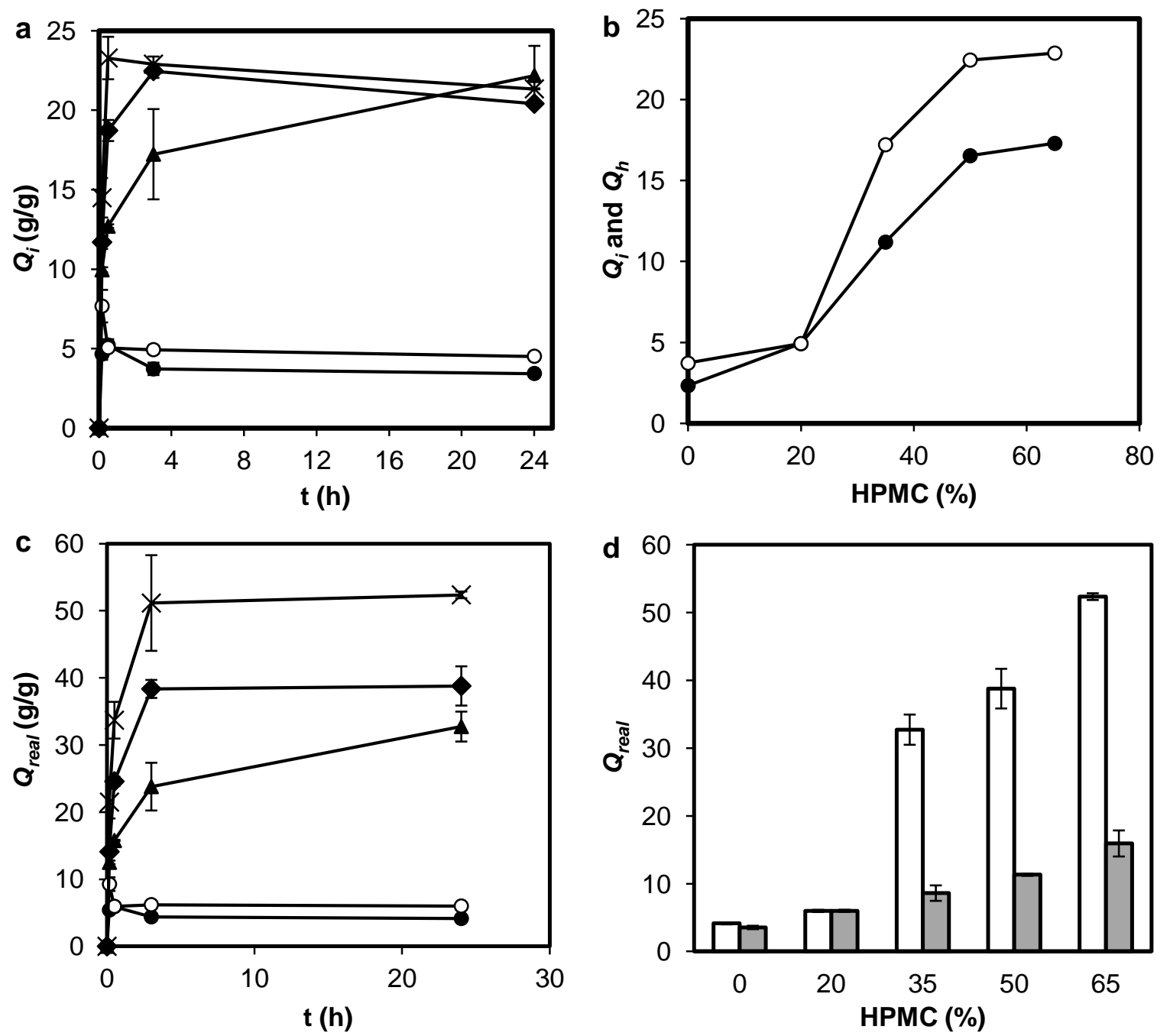
Figure 5
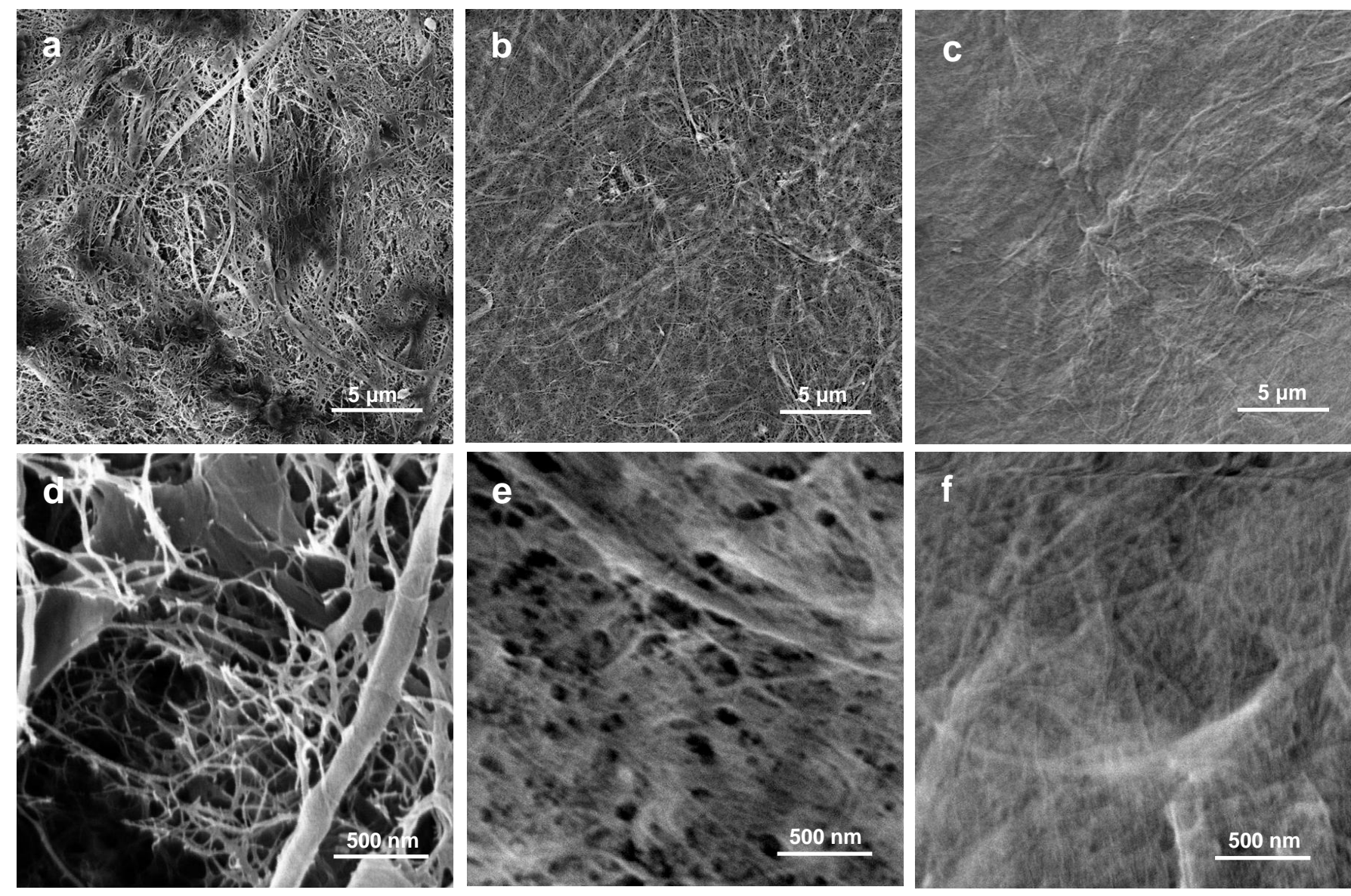


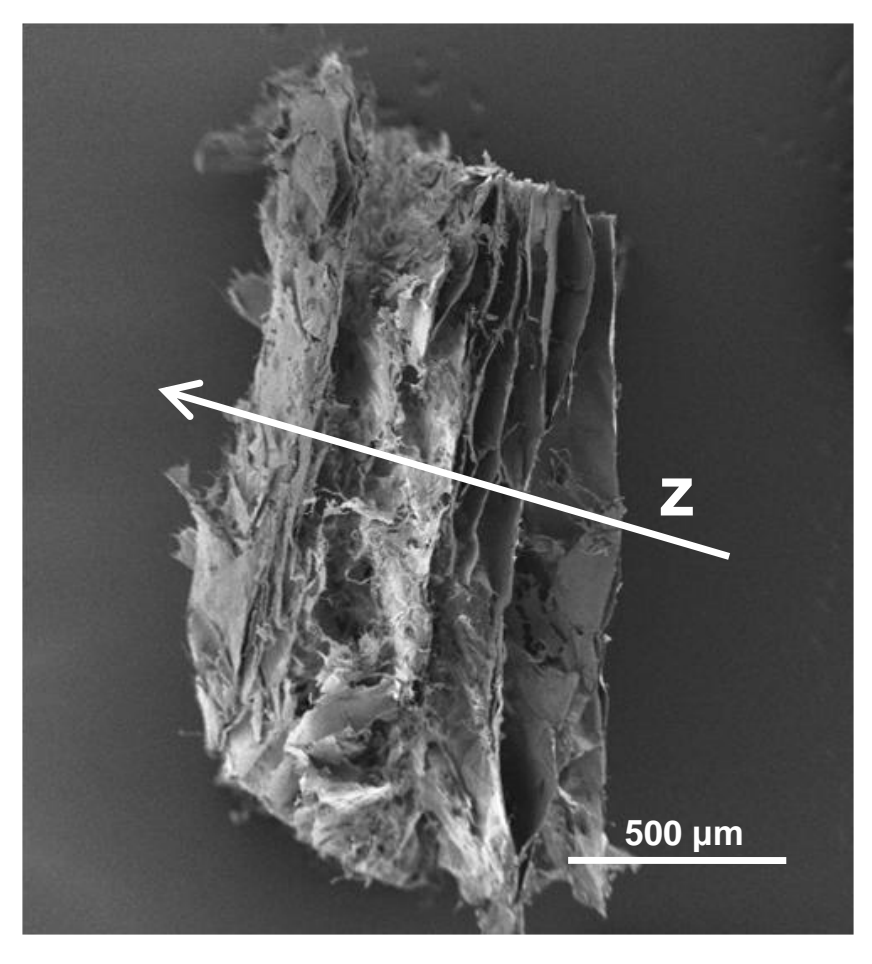

Figure 6

$\kappa$

$500 \mu \mathrm{m}$

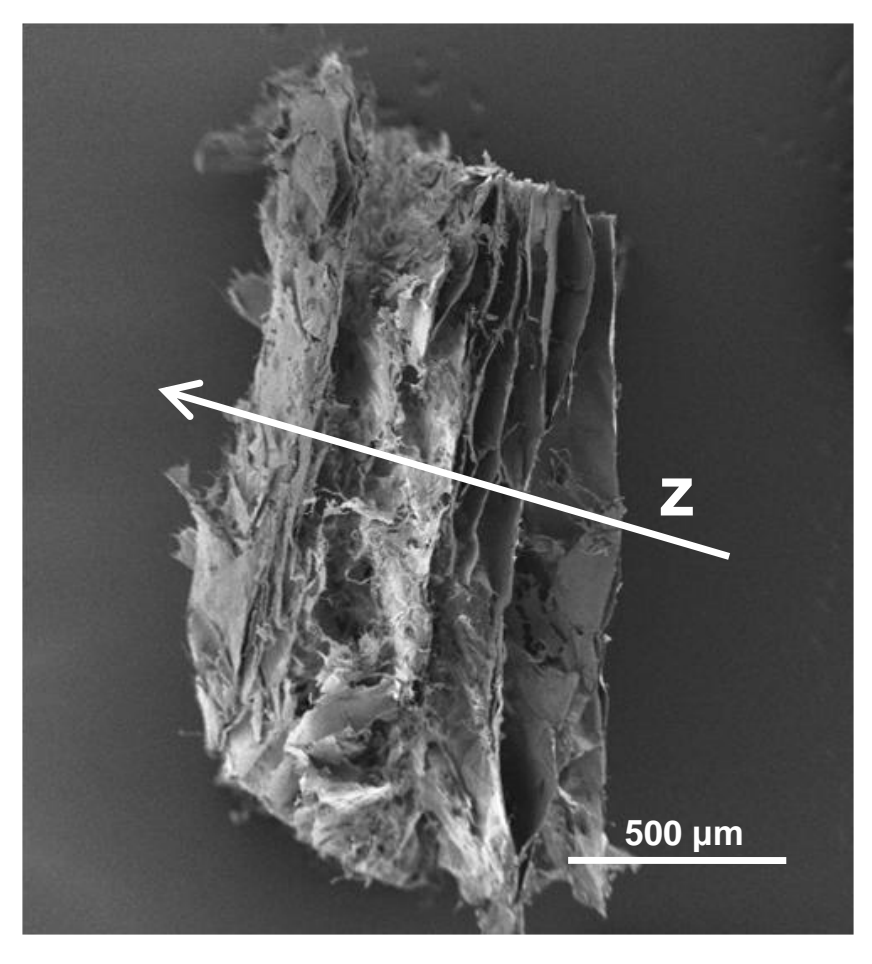


Figure 7

Swelling of inter-layer regions

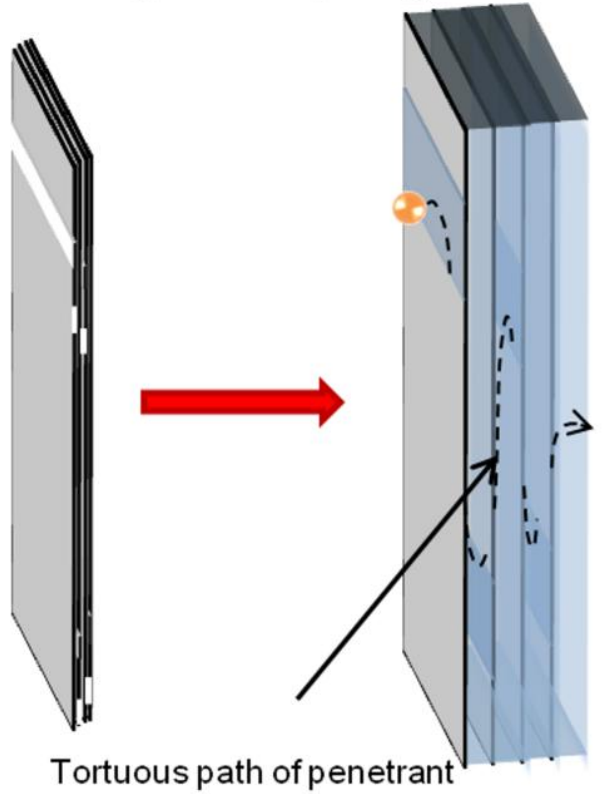


Figure 8
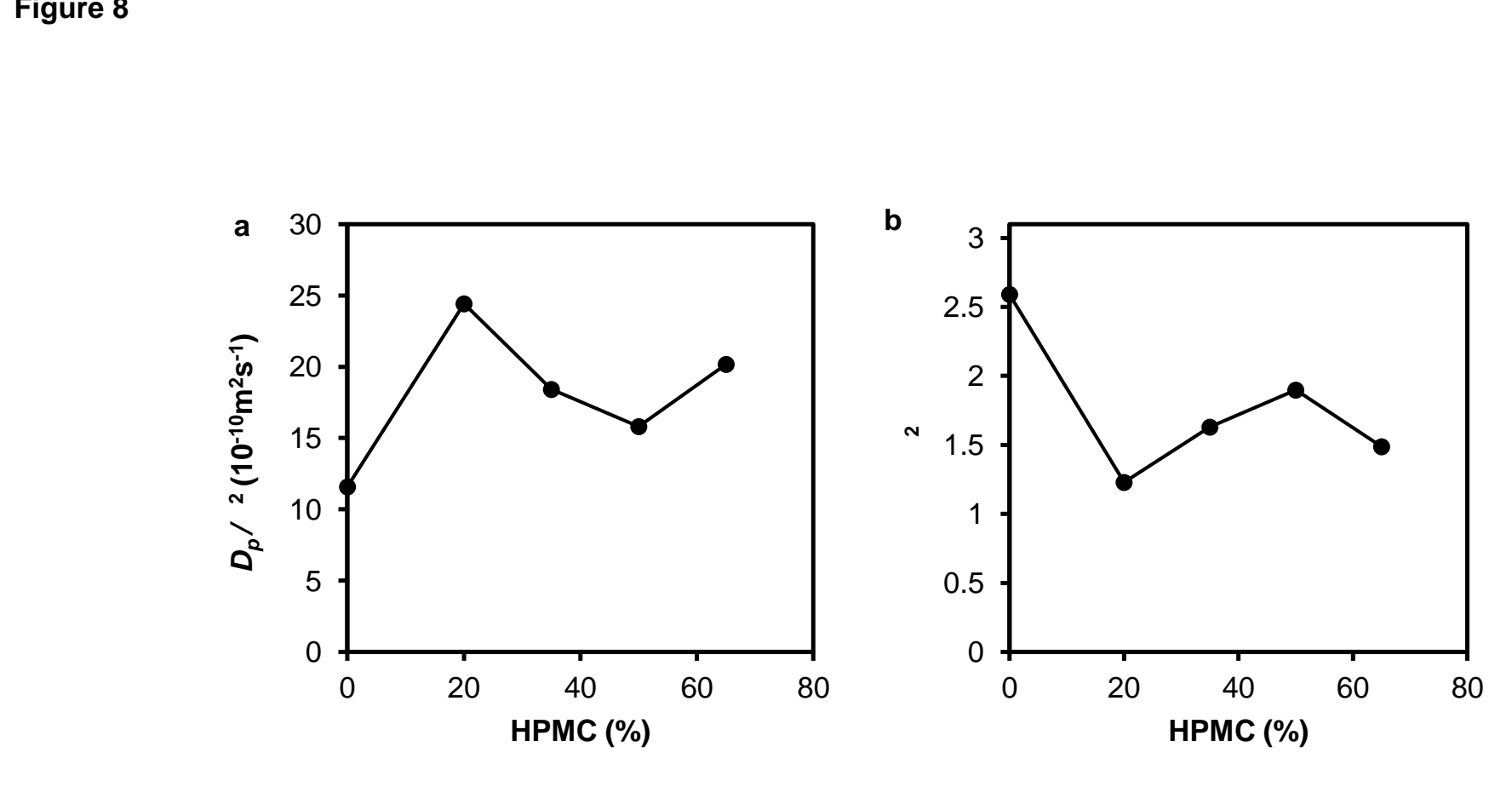

$$
0
$$

.

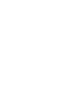
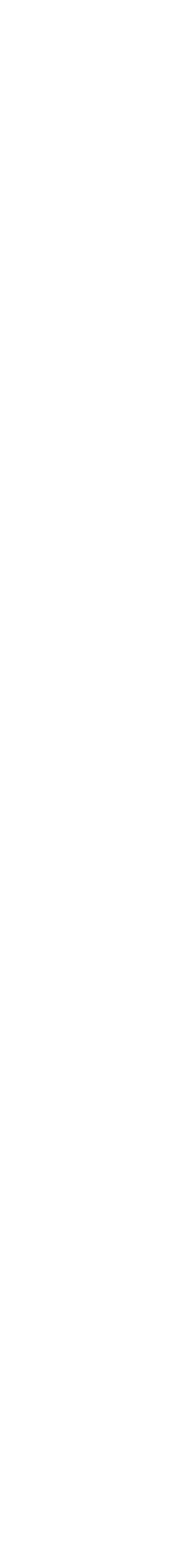


\section{Supplementary material}

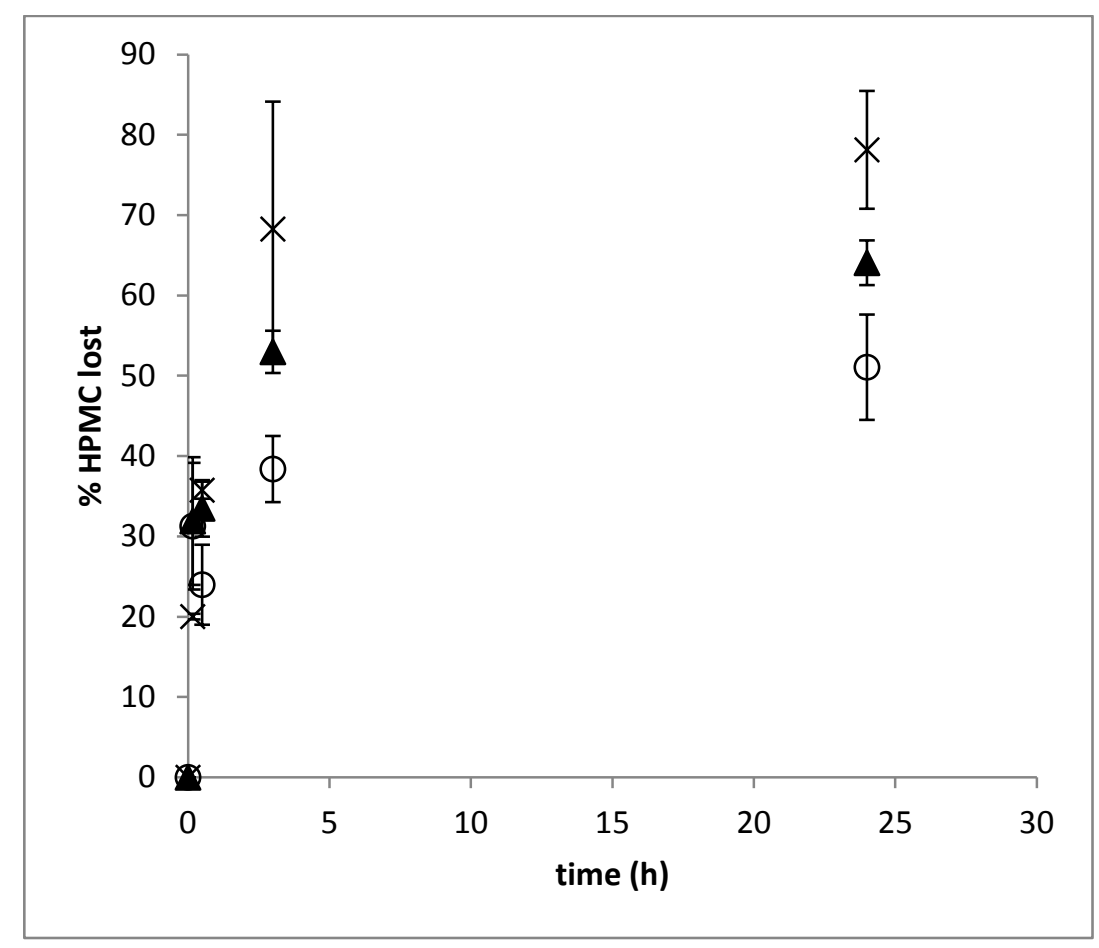

Supplementary figure 1. Percentage of HPMC released at different times for MFC-HPMC films with $20 \%$ (०), $35 \%$ ( $\mathbf{\Delta})$ and $50 \%(\times)$ w/w HPMC, determined through mass loss of the films, assuming that the fraction of the MFC release was the same as in pure MFC films $(\sim 15$ $\%)$.

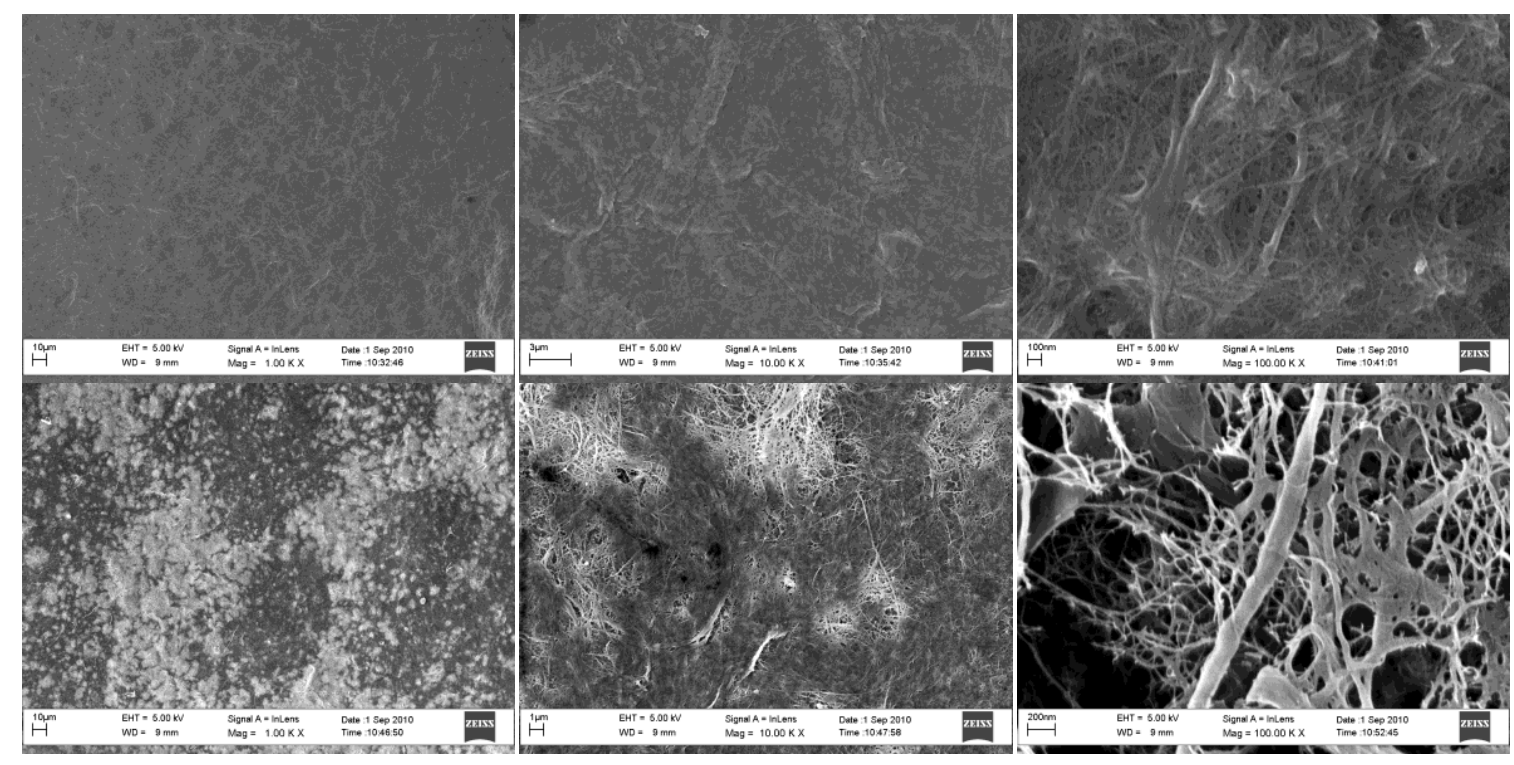

Supplementary figure 2. SEM images of pure MFC films after submersion for $3 \mathrm{~h}$ and subsequent drying, top row is dried conventionally, bottom row is freeze dried. There are obvious structural differences, most likely due to aggregation during conventional drying. White areas are due to charge buildup. 

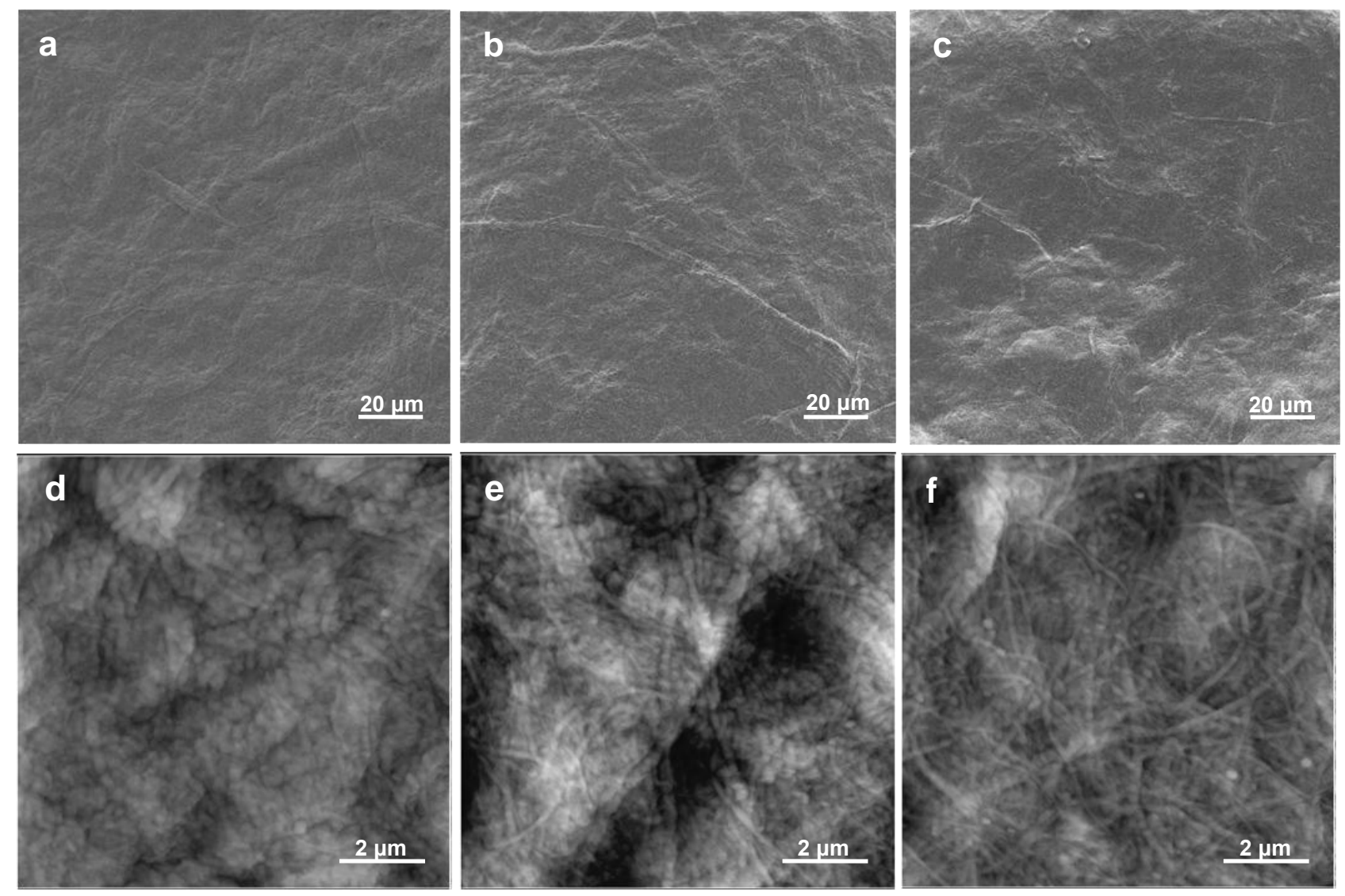

Supplementary figure 3. Micrographs of MFC-HPMC films, as prepared. Top row are SEM images of films with: (a) $0 \%$, (b) $20 \%$ and (c) $50 \%$ w/w HPMC. Bottom row are AFM images of films with: (d) $0 \%$, (e) $20 \%$ and (f) $50 \% \mathrm{w} / \mathrm{w}$. 